\title{
A CASE OF IDIOPATHIC PULMONARY HAEMOSIDEROSIS WITH MYOCARDITIS
}

\author{
BY \\ S. CAMPBELL and C. A. J. MACAFEE \\ From the Royal Belfast Hospital for Sick Children ana the Department of Pathology. the Queen's University of Belfast
}

(RECEIVED FOR PUBLICATION DECEMBER 1, 1958)

Idiopathic pulmonary haemosiderosis is a not uncommon condition characterized clinically by anaemia, haemoptysis, and radiological changes in the lung fields. It was first described by Ceelen (1931), and the clinical and pathological findings of the disease have been fully reviewed by Wyllie, Sheldon, Bodian and Barlow (1948). This case is presented because of the association of myocarditis with the pulmonary lesions of idiopathic pulmonary haemosiderosis.

\section{Case History}

The black rectangles on the diagram indicate the hospital admissions of the patient (Fig. 1). He was first seen at the age of 7 in 1950 when he complained of increasing tiredness and shortness of breath of five months' duration. He was the eleventh child in a family of 12 , the remainder of whom are quite healthy. On examination he was a thin, pale child with an enlarged liver, but there were no other abnormal clinical findings.

He was admitted for investigation and his blood picture showed an iron deficiency anaemia with a haemoglobin of $7.4 \mathrm{~g} . / 100 \mathrm{ml}$. (50\%). Unfortunately at this time he had Sonne dysentery and was transferred to the Fever Hospital.

He was next seen in 1953 when again he had a history of pallor, and was now coughing and spitting up blood. On admission to hospital his blood picture showed an iron deficiency anaemia with a haemoglobin of $5.75 \mathrm{~g} . /$ $100 \mathrm{ml}$. (39\%). His serum bilirubin was $0.2 \mathrm{mg}$. \% His liver function tests were normal but he had an increase of urobilinogen in his urine. A barium swallow and radiographs of the chest showed nothing of note. $\mathrm{He}$ was trarsfused with blood and discharged on oral iron.

He remained relatively well during 1954 but was readmitted in January, 1955, as his haemoglobin had again fallen to $5.05 \mathrm{~g} . / 100 \mathrm{ml}$. (34\%). He was again transfused. In March, 1955, he had an oesophagoscopy and punch liver biopsy done by Professor H. W. Rodgers. Both these investigations gave normal findings.
In November, 1955, he had a phlyctenular conjunctivitis, and in view of this had a radiograph of the chest which showed widespread areas of consolidation. At this time the diagnosis of acute idiopathic pulmonary haemosiderosis was made by Dr. O. D. Fisher, on the basis of the history of haemoptysis, episodes of profound anaemia, and the radiographic pulmonary changes. This diagnosis was confirmed by a lung aspiration biopsy which showed haemosiderin-laden macrophages. There was a reticulocytosis of $33 \%$ in his peripheral blood at this time and his bone marrow showed a marked erythropoiesis. An E.C.G. was normal.

In February, 1956, he had a splenectomy done by Professor H. W. Rodgers, and following this he was well

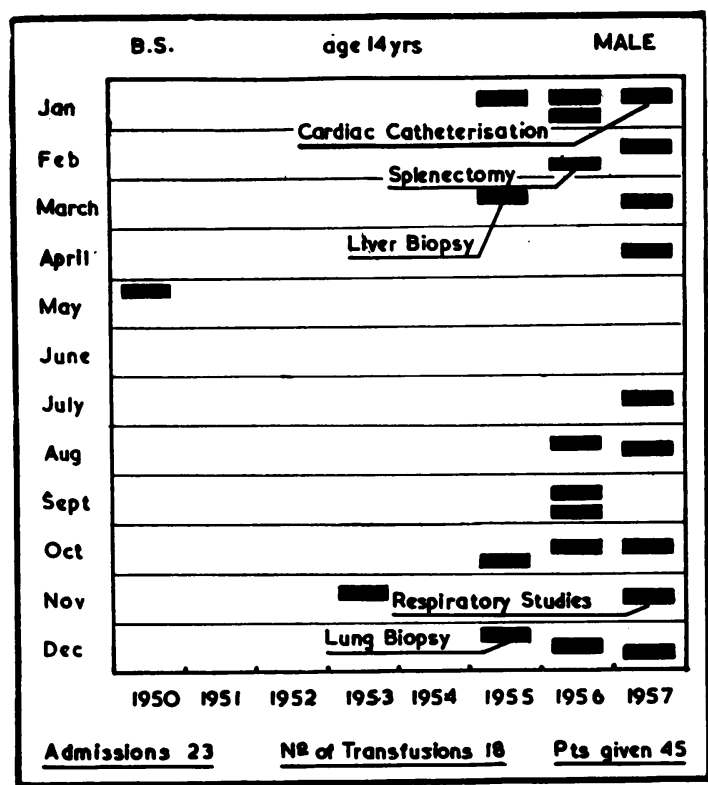

FIG. 1.-Chart of hospital admissions and investigations performed. 
until August, 1956, when his haemoglobin had again fallen and he required transfusions.

In January, 1957, cardiac catheterisation was carried out by Dr. J. F. Pantridge and the findings excluded pulmonary hypertension.

In March, 1957, haemosiderin was demonstrated in his gastric washings. Treatment with cortisone was then commenced, but was without effect and the drug was discontinued in October when he was admitted with fever and sudden onset of severe pain in the left lumbar region. His urine showed evidence of a coliform infection which was treated with an eight-day course of chloramphenicol.

In November, 1957, he was admitted in cardiac failure. He had cyanosis, peripheral oedema, crepitations at both bases, and gross hepatomegaly. He responded well to digoxin and his haemoglobin rose spontaneously from $8.88 \mathrm{~g} . / 100 \mathrm{ml}$. $(60 \%)$ to $13.3 \mathrm{~g} . / 100 \mathrm{ml}$. $(90 \%)$. Following this respiratory studies were carried out by Professor O. L. Wade who reported that the findings were compatible with lung fibrosis.

He was readmitted in December, 1957, again in gross cardiac failure, and with a haemoglobin of $9 \cdot 2 \mathrm{~g} . / 100 \mathrm{ml}$. $(62 \%)$. He died within a few hours in cardiac failure and there were no symptoms of a pulmonary crisis. At no time was there any jaundice or finger clubbing.

He had a fever only on two occasions, when he had a urinary infection and when he was in cardiac failure.

Findings at Autopsy. The body was that of a 14-yearold boy of small stature and average nutrition. There were no palpable superficial lymph nodes or other external lesions of note. The main pathological lesions were in the lungs, heart, lymph nodes and left kidney.

The heart weighed $250 \mathrm{~g}$. and was enlarged for a boy of this age. No congenital or other valvular lesions were present. The right ventricle was hypertrophied, measuring $9 \mathrm{~mm}$. The left ventricle was dilated, its endocardium was rather opaque, and the myocardium mottled, with pale areas suggestive of fibrosis (Fig. 2). No mural thrombi were noted.

The lungs showed a striking picture. In situ they failed to collapse when the chest wall was opened and each had a blotchy red pleural surface. On section they were of a deep rusty colour with intense congestion and a poorly defined alveolar pattern at the bases, whereas at the apices the alveolar pattern was more distinct The cut surface gave a uniformly positive prussian blue reaction for iron (Fig. 3).

The hilar and paratracheal lymph nodes were markedly enlarged (the largest being $5 \times 3 \times 2 \mathrm{~cm}$.) and gave a positive reaction for iron.

The liver was enlarged (1,100 g.) and showed only terminal congestion.

The right kidney (130 g.) was normal in appearance. The left kidney $(60$ g.) showed a healed infarct involving the upper two-thirds of the renal substance.

The brain, bone marrow, and all other organs were normal.

Histological Examination. Heart : many sections of the left ventricle were examined and all showed a marked degree of fibrosis, chiefly in the inner third of the myocardium. There were infiltrations of polymorphs, large mononuclears and lymphocytes between the patches of fibrosis, and eosinophils were noted in some areas. The picture was that of a myocarditis of some duration and probably progressive at the time of death. There were no deposits of iron in the myocardium (Fig. 4).

Lungs : many sections were studied and the following different features were noted. Many haemosiderin-filled macrophages were seen lying in foci in the alveoli, and also a few in the interstitial tissues. There was evidence of terminal haemorrhage with red blood cells in the air spaces. The alveolar walls showed extensive fibrosis with much thickening of the parenchyma. The walls of the small arteries showed a number of striking features. In haematoxylin and eosin sections the elastic tissue was often fragmented and stained dark blue. It gave a positive prussian blue reaction for iron. The fragmentation was associated with accumulations of giant cells sometimes forming ill-defined granulomata (Figs. 5 and 6). A few of the vessels showed an acute arteritis, with necrosis of their walls, and infiltrations of polymorphonuclear leucocytes and lymphocytes in all coats (Fig. 7). The elastic tissue of the alveolar septa showed a similar alteration with much iron impregnation and fragmentation.

Paratracheal lymph nodes: the sinuses were filled with large numbers of iron-containing macrophages. Vascular changes were also present, the elastica of the blood vessels within the lymph nodes showing iron impregnation, fragmentation and giant cell reaction, as found in the lung. There were also many plasma cells scattered throughout the lymph node.

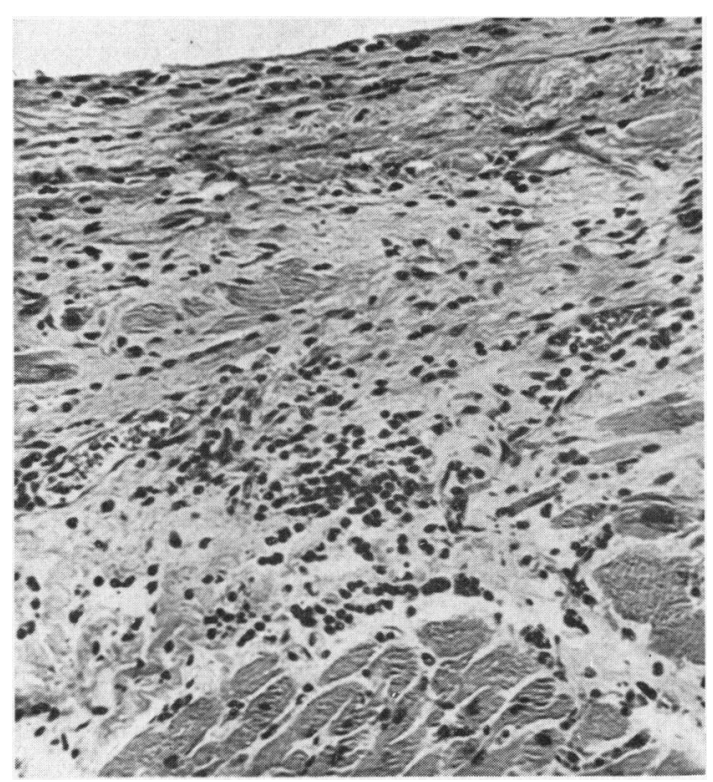

FIG. 4.-Section of the myocardium showing subendocardial fibrosis and inflammatory cell infiltration. H. and E. $\times 100$. 


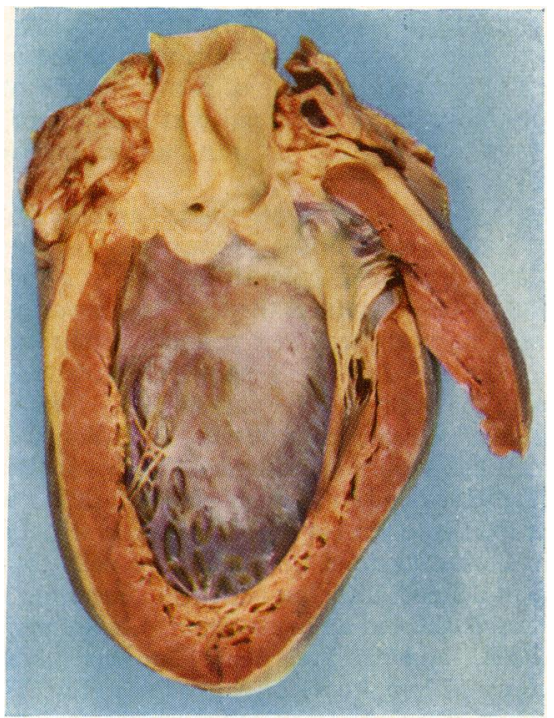

FIG. 2.-Heart showing left ventricular dilatation with patchy fibrosis of the myocardium.

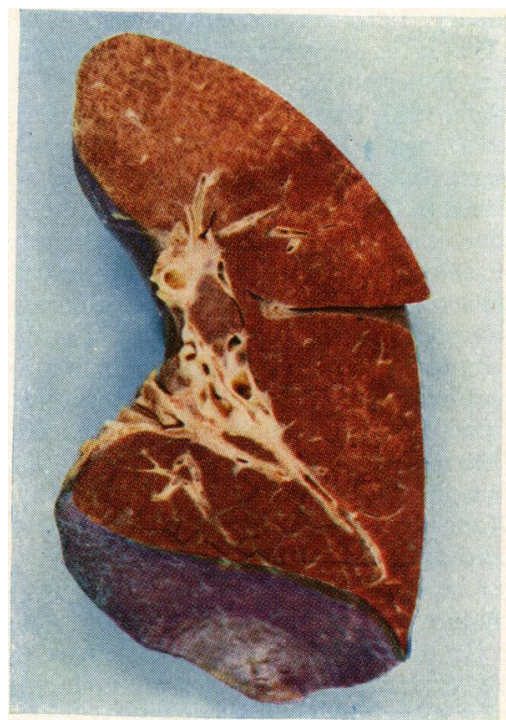

Fig. 3.-Right lung showing intense haemosiderin staining of the cut surface.

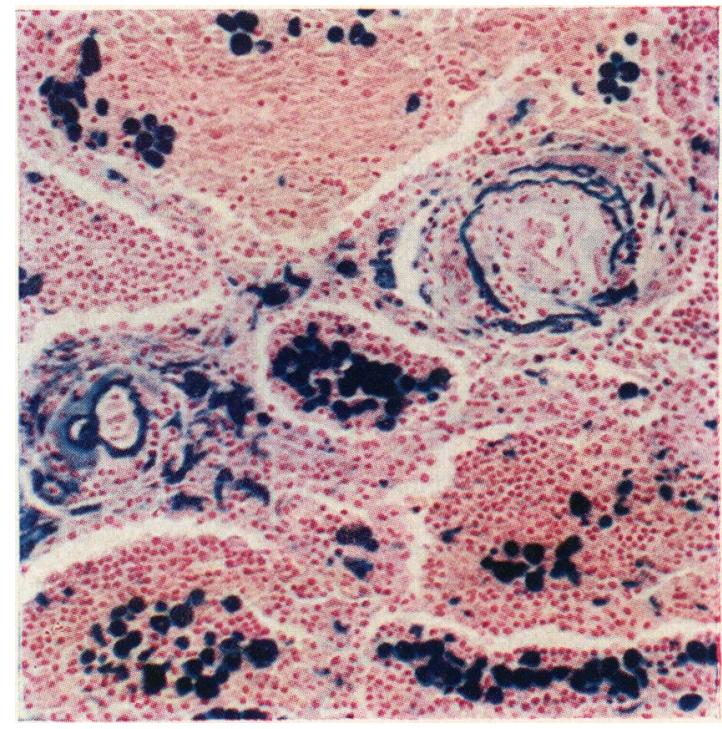

Fig. 5.-Section of the lung showing iron filled macrophages in air spaces and impregnation of elastic tissue of blood vessels with iron.

Stained by Perls' method. $\times 100$. 


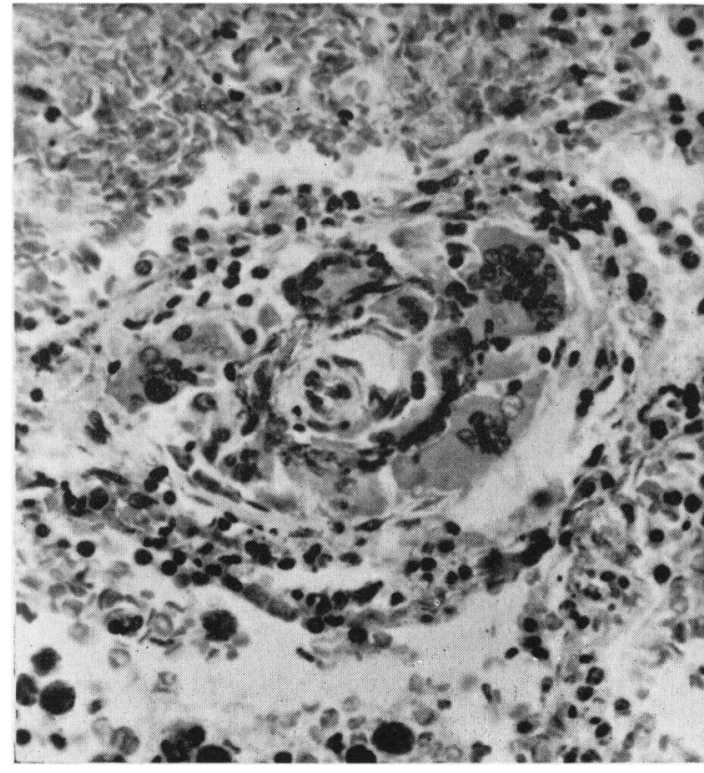

Fig. 6.-Section of small pulmonary artery showing iron impregnation and fragmentation of the elastic fibres with marked giant cell reaction. $\mathrm{H}$. and $\mathrm{E} . \times 350$.

No iron was found in the sections of liver, spleen or bone marrow.

\section{Discussion}

The diagnosis of idiopathic pulmonary haemosiderosis was suspected clinically in this case by the presence of anaemia, recurring haemoptyses, and radiological changes in the lung fields, the diagnosis being confirmed by lung biopsy. The autopsy findings, while in keeping with this diagnosis, show one or two unusual features. The occurrence of a myocarditis, for example, is of some interest. It is well known that pulmonary haemosiderosis may develop secondary to advanced cardiac failure such as in mitral stenosis, occasionally hypertension, and other lesions of the left side of the heart. The possibility of a relationship of this myocarditis to the pulmonary lesions must therefore be considered. Review of the literature reveals that some form of myocarditis in association with idiopathic pulmonary haemosiderosis is not a rare occurrence.

At present about 70 cases of idiopathic pulmonary haemosiderosis have been reported. Out of 65 of these, 28 have been confirmed by autopsy; in five it was stated that a 'myocarditis' or 'myocardial change' was present (Gellerstedt, 1939; Glanzmann and Walthard, 1941; Waldenström, 1944; Scheidegger and Dreyfuss, 1945; Soergel, 1957). However, in only eight cases is a histological examination of the myocardium mentioned: Soergel, though he

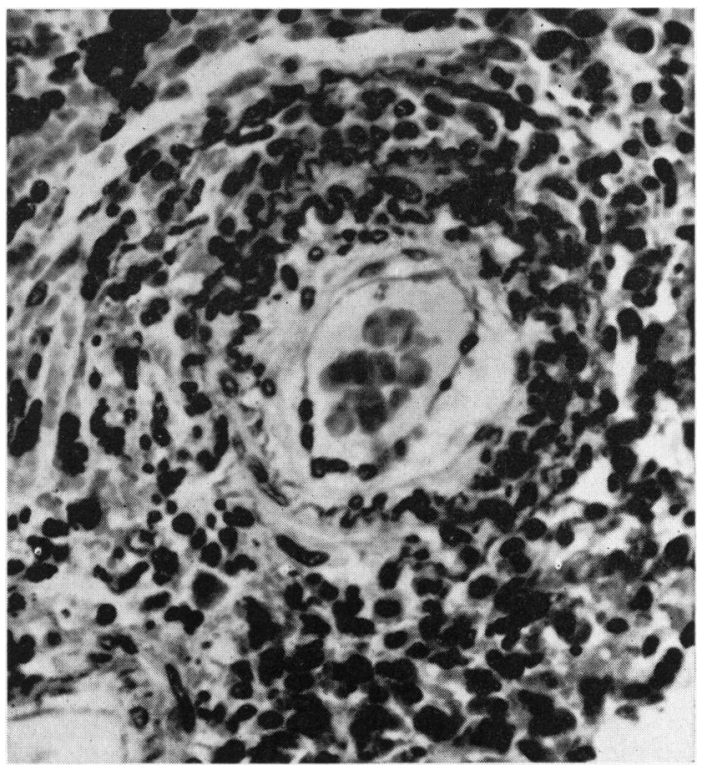

FIG. 7.-Section of pulmonary artery showing arteritis with inflammatory reaction in all coats. H. and E. $\times 350$.

mentioned two cases with a subacute myocarditis, does not describe what histological changes were seen. Wigod (1955) reported a case in a child aged 15 months in which the heart weighed $85 \mathrm{~g}$. (normal weight $47 \mathrm{~g}$.). The right ventricle was $3 \mathrm{~mm}$. thick and the left $8 \mathrm{~mm}$. Histologically there was some vacuolation of the muscle fibres due to fat. Another case worth noting is that of Walton and Williams (1951) in a man aged 19 years, who died in heart failure. At autopsy the heart was enormously enlarged, weighing $1 \cdot 1 \mathrm{~kg}$. Unfortunately no histological examination of the myocardium is described. It is difficult to explain such gross cardiac enlargement merely as a result of the pulmonary lesions. It is evident therefore that pulmonary and cardiac changes may occur together in this disease.

As far as the lungs are concerned these showed all the characteristic features that have been described in idiopathic pulmonar $v$ haemosiderosis, namely, the iron-filled macrophages, the alveolar haemorrhages, the thickening of the alveolar walls, and changes in the elastic tissue in the vessels and the alveolar walls. The associated arteritis has previously been described by Anspach (1939). Similarly the hilar lymph nodes are typical in that they contain iron-filled macrophages. One feature that has not previously been reported, as far as we are aware, is the great number of plasma cells in the lymph nodes, but their significance is uncertain. 
Ceelen (1931) originally suggested that the pulmonary lesions were due to a primary elastic tissue disorder. However, the pulmonary lesions are now believed to develop as a result of a local excess of iron from repeated haemorrhages. The iron becomes deposited in the parenchyma and particularly in the elastic tissue fibres. These fibres in turn undergo fragmentation which then stimulates a foreign body giant cell reaction. The same appearances occurred in the blood vessels in the lymph nodes where there was also a heavy local deposition of iron. Similar fragmentation of the elastica and foreign body granulomata may be seen in the metastatic calcification of the lung occurring in myelomatosis. This supports the idea that the elastic tissue changes are merely secondary but leaves unsolved the problem of what is the basic defect which allows haemorrhage to occur. The possibility of an allergic mechanism has been suggested by Steiner (1954).

A very similar picture can be found in the lungs in mitral stenosis of long duration (Lendrum, 1950). The main difference is that in mitral stenosis the iron-filled macrophages are arranged in foci and the hilar lymph nodes contain little or no iron. But this may be purely a difference of degree. What one must, in fact, consider, is whether the pulmonary lesion in this case is truly idiopathic, or secondary to the left ventricular failure from the myocarditis. One year before death it was found that pulmonary hypertension was not present on cardiac catheterisation. This tends to exclude a long period of heart failure though terminally there was gross heart failure. On the whole, however, the pulmonary changes were more advanced than is normally seen in pulmonary haemosiderosis of cardiac origin, and the case is therefore more likely to be of the idiopathic type. A further possibility exists, that the tussues of the heart and lungs are attacked simultaneously by the same aetiological agent, the nature of which is at present unknown.

Though it is impossible to reach any definite conclusion as to the relationship of the myocarditis to the pulmonary lesions, it is felt that closer clinico-pathological study including histological examination of the heart should be made in all cases of this nature. In the past most attention has been focused on the pulmonary lesions, and the myocardium has not always been investigated histologically.

The only other incidental finding was that of the renal infarct, which has been reported on one other occasion (Schoeniger, Tucker and Bolande, 1958). In this present case it was probably of embolic origin from the left ventricle.

\section{Summary}

A case of 'idiopathic' pulmonary haemosiderosis in a boy of 14 years is reported. The condition which was diagnosed clinically by gastric washings and lung biopsy, was confirmed at autopsy.

Therapy with splenectomy and cortisone was used without effect.

A severe myocarditis was found and its possible relationship to the pulmonary lesions is discussed.

We wish to thank Professor F. M. B. Allen for permission to publish the clinical details of this case. We are also indebted to Professor J. H. Biggart and Dr. E. F. McKeown for much helpful criticism and advice. The photography is the work of Mr. D. Mehaffey. We also thank the Northern Ireland Hospital Authority for a grant in aid of publication.

\section{REFERENCES}

Anspach, W. E. (1939). Amer. J. Roentgenol., 41, 592.

Ceelen, W. (1931). In Handbuch der speziellen pathologische Anatomie und Histologie, ed. F. Henke and $O$. Lubarsch, band 3, teil 3, p. 20. Springer, Berlin.

Gellerstedt, N. (1939). Acta path. microbiol. scand., 16, 386

Glanzmann, E. and Walthard, B. (1941). Mschr. Kinderheilk., 88, 1 Lendrum, A. C. (1950). J. Path. Bact., 62, 555.

Scheidegger, S. and Dreyfus, A. (1945). Ann. Paediat. (Basel),

165, 2.
Schoeniger, E. L., Tucker, A. S. and Bolande, R. P. (1958). Radioology, 70, 191

Soergel, K. H. (1957) Pediatrics, 19, 1101.

Steiner, B. (1954). Arch. Dis. Childh., 29, 391.

Waldenström, J. (1944). Acta radiol.' (Stockh.), 25, 149.

Walton, M. and Williams, A. A. (195i). Brit. med. J., 2, 390.

Wigod, M. (1955). New Engl. J. Med., 253, 413.

Wyllie, W. G., Sheldon, W., Bodian, M. and Barlow, A. (1948). Quart. J. Med., (n.s.) i7, 25. 